\title{
Ovarian and hormonal response of female goats to active immunization against inhibin
}

\author{
M S Medan ${ }^{1,2}$, G Watanabe ${ }^{1,3}, \mathrm{~K}$ Sasaki $^{4}$, Y Nagura $^{5}$, \\ H Sakaime $^{5}$, M Fujita ${ }^{5}$, S Sharawy ${ }^{2}$ and K Taya ${ }^{1,3}$ \\ ${ }^{1}$ Laboratory of Veterinary Physiology, Tokyo University of Agriculture and Technology, 3-5-8 Saiwai-cho, Fuchu, Tokyo 183-8509, Japan \\ ${ }^{2}$ Department of Theriogenology, Faculty of Veterinary Medicine, Suez Canal University, Ismailia, Egypt \\ ${ }^{3}$ Department of Basic Veterinary Sciences, United Graduate School of Veterinary Sciences, Gifu University, Gifu 501-1193, Japan \\ ${ }^{4}$ Hitachi Ltd, Central Research Laboratory, Tokyo 185-8601, Japan \\ ${ }^{5}$ National Livestock Breeding Centre, Nagano Station, Nagano, Japan \\ (Requests for offprints should be addressed to K Taya; Email: taya@cc.tuat.ac.jp)
}

\begin{abstract}
This study was conducted to evaluate the effect of active immunization against inhibin on hormonal levels and the ovulation rate in goats. Ten adult Shiba goats (Capra hircus) in two groups were used in this study. The first group was injected with inhibin vaccine (immunized, $n=5$ ) and the second group was injected with Freund's adjuvant (control, $n=5$ ) followed by three booster injections at 4-week intervals. After the third booster injection, three consecutive periods of oestrus were induced using prostaglandin $\mathrm{F}_{2 \alpha}$ at intervals of 11 days. Blood samples were collected at 2-6 h intervals and the ovaries were monitored using B-mode ultrasonography. All inhibin-immunized goats generated antibodies that bound ${ }^{125}$ I-labelled bovine inhibin and their FSH concentrations were significantly
\end{abstract}

higher than corresponding values in the control group. Also, inhibin-immunized goats had significantly higher preovulatory oestradiol-17 $\beta(P<0 \cdot 01)$ and higher concentrations of progesterone in the luteal phase $(P<0 \cdot 05)$. Immunization of goats against inhibin resulted in a significant $(P<0 \cdot 01)$ increase in ovulation rate (control: $1 \cdot 7 \pm 0 \cdot 3$ vs immunized: $7 \cdot 6 \pm 1 \cdot 1)$.

These results demonstrate that active immunization against inhibin enhances ovarian follicular development and ovulation rate by promoting an increase in pituitary FSH secretion. Therefore, immunization against inhibin may be a useful alternative to the conventional approach of superovulation in goats.

Journal of Endocrinology (2003) 177, 287-294

\section{Introduction}

In domestic animals, the induction of multiple ovulations is possible by potentiating the stimulatory effects of the endogenous gonadotrophin by administering hormones with follicle-stimulating hormone (FSH)-like activity or by removing the inhibitory action of ovarian hormones on gonadotrophin release by the hypothalamus-pituitary axis. Considerable interest has been placed on inhibin, which by a synergistic action with oestradiol is involved in the negative feedback regulation of FSH at the anterior pituitary (Findlay \& Clarke 1987, Findlay et al. 1992, Taya 1993, Taya \& Watanabe 1999) thereby controlling ovulation rates. Purification and partial characterization of the inhibin molecule revealed that both inhibin forms (A and B) share a common $\alpha$-subunit, but different $\beta$-subunits (Ling et al. 1985). Also, the $\beta$-subunits were found to exist in dimeric forms (activins), often with opposite biological activity to inhibin (Ling et al. 1986, Vale et al. 1986). These observations suggest that the $\alpha$-subunit, but not the $\beta$-subunit, could be suitable as an immunogen to neutralize the activity of both inhibin forms. Domestic and laboratory animals have been immunized against a variety of inhibin preparations, and increases in ovulation rate have been reported in mares (McCue et al. 1992), sheep (Mizumachi et al. 1990, Wrathall et al. 1990, 1992, Wheaton et al. 1992. Anderson et al. 1998), cattle (Glencross et al. 1994), goats (Dietrich et al. 1995, Hennies et al. 2001) and guinea pigs (Shi et al. 2000). Although most studies revealed that passive immunization against inhibin increased FSH levels (Campbell \& Scaramuzzi 1995, Kusina et al. 1995, Akagi et al. 1997, Takedomi et al. 1997, Nambo et al. 1998, Shi et al. 1999), there were conflicting results about the effect of active immunization against inhibin on FSH secretion.

The objective of this study was to determine the effect of active immunization against inhibin on gonadotrophins, oestradiol or progesterone secretion and ovulation rate in goats. 


\section{Materials and Methods}

\section{Preparation of the immunogen}

The immunogen used (inhibin vaccine) was a synthetic peptide, corresponding to the $\mathrm{N}$-terminal sequence (1-26) of the $\alpha$-subunit of porcine inhibin conjugated to rabbit serum albumin as described previously (Konishi et al. 1996). For immunization, $100 \mu \mathrm{g}$ synthetic peptide per dose were dissolved in $1 \mathrm{ml}$ PBS and emulsified with an equal volume of Freund's complete adjuvant.

\section{Animals and treatment}

Ten adult Shiba goats (Capra hircus) were used in this study. The animals were housed under natural daylight and fed $700 \mathrm{~g} /$ animal of hay cubes daily. Mineral salt blocks and water were freely available. Oestrous cycles were synchronized with two injections of $125 \mu \mathrm{g}$ of a synthetic analogue of prostaglandin $\mathrm{F}_{2} \alpha\left(\mathrm{PGF}_{2} \alpha\right)$ (Estrumate; Schering Plough Animal Health, NJ, USA) 11 days apart. Oestrus was detected using an aproned mature buck every $6 \mathrm{~h}$. On day 10 of the oestrous cycle, animals were allocated to two groups: the immunized group $(n=5)$ treated with s.c. injections of $1 \mathrm{ml}$ inhibin vaccine emulsified in $1 \mathrm{ml}$ Freund's complete adjuvant into four different sites followed by three booster injections at 4 -week intervals and the control group $(n=5)$ treated with s.c. injections of $1 \mathrm{ml}$ saline emulsified in $1 \mathrm{ml}$ Freund's complete adjuvant. After the third booster injection, oestrous cycles were synchronized by i.m. injection of $125 \mu \mathrm{g} \mathrm{PGF}{ }_{2} \alpha$. Two further $\mathrm{PGF}_{2} \alpha$ injections were given at 11-day intervals to shorten oestrous cycles by inducing luteolysis. The experimental protocol was approved in accordance with the Guide for the Care and Use of Laboratory Animals prepared by Tokyo University of Agriculture and Technology.

\section{Blood samples for inhibin antibody titres and hormone concentrations}

For examination of titres of inhibin antibodies, blood samples were collected by jugular venepuncture once per week. After the third booster immunization, blood samples were collected every $6 \mathrm{~h}$ for 2 days before PGinduced luteolysis, every $2 \mathrm{~h}$ from 48 to $72 \mathrm{~h}$ after PG injection to detect the luteinizing hormone (LH) surge, then every $6 \mathrm{~h}$ until the next PG injection. The same regimen of sampling was repeated during the next cycle to determine gonadotrophin level. Oestradiol-17 $\beta$ and progesterone were determined in daily blood samples. Blood samples were collected into heparinized Vacutainer tubes (Venoject II; Terumo, Tokyo, Japan), centrifuged at $1200 \mathrm{~g}$ for $15 \mathrm{~min}$, and plasma was separated and stored at $-20{ }^{\circ} \mathrm{C}$ until assayed for hormones.
Assessment of inhibin antibody titres

Changes in inhibin binding activity in plasma were determined by measuring the binding of ${ }^{125}$ I-labelled inhibin (5000 c.p.m.) as reported previously (Kaneko et al. 1993). Plasma samples were diluted 1:10 with PBS containing 5\% BSA. PBS $(100 \mu \mathrm{l})$ was added to each aliquot $(100 \mu \mathrm{l})$ of diluted plasma and incubated for $24 \mathrm{~h}$ at $37^{\circ} \mathrm{C}$ with ${ }^{125}$ I-labelled bovine $32 \mathrm{kDa}$ inhibin. Bound tracer was then separated by adding $100 \mu \mathrm{l}$ PBS containing 1\% bovine gamma globulin and $500 \mu \mathrm{l}$ PBS containing 25\% polyethylene glycol (molecular mass $6000 \mathrm{Da}$ ), mixing for 3 min, centrifuging at $1200 \mathrm{~g}$ for $30 \mathrm{~min}$ at $4{ }^{\circ} \mathrm{C}$ and then counting the radioactivity in the precipitate. Inhibinbinding activity was expressed as a percentage of the total counts added.

\section{Ultrasound examination}

The ovaries were monitored using a B-mode scanner (ECHOPAL ultrasound scanner; Hitachi Medical Corporation, Tokyo, Japan) equipped with a $7 \cdot 5 \mathrm{MHz}$ transducer transrectally every $12 \mathrm{~h}$ from PG injection until the end of oestrus and on day 7 post-ovulation to count corpora lutea. The occurrence of ovulation was assessed as the disappearance of large antral follicles present at the previous ultrasonography examination confirmed by detection of corpora lutea on day 7 post-ovulation. Ovulation rate was determined by matching the number of large antral follicles that disappeared with the number of corpora lutea detected (Pierson \& Ginther 1988).

\section{Hormone analysis}

Plasma concentrations of FSH were measured by RIA as described by Araki et al. (2000) using anti-ovine FSH, National Institute of Diabetes and Digestive and Kidney Diseases (NIDDK)-FSH-I-1 for radioiodination, and NIDDK-oFSH-RP-1 as a reference standard. Plasma concentrations of LH were measured by RIA as described by Mori \& Kano (1984) using anti-ovine LH (YM No. 18), NIDDK-oLH-I-3 for radioiodination, and NIDDKoLH-RP-24 as a reference standard. The intra- and interassay coefficients of variation were 9.8 and $12.6 \%$ for FSH and 5.9 and $6.5 \%$ for $\mathrm{LH}$ respectively. Plasma concentrations of oestradiol-17 $\beta$ and progesterone were determined by a double-antibody RIA system using ${ }^{125}$ I-labelled radioligands as described previously (Taya et al. 1985). Antisera against oestradiol-17 $\beta$ (GDN 244) and progesterone (GDN 337) were kindly provided by $\mathrm{Dr}$ G D Niswender (Animal Production and Biotechnology, Colorado State University, Fort Collins, CO, USA). The intra- and interassay coefficients of variation were 5.7 and $7 \cdot 4 \%$ for oestradiol $-17 \beta$ and $8 \cdot 2$ and $9 \cdot 2 \%$ for progesterone respectively. 


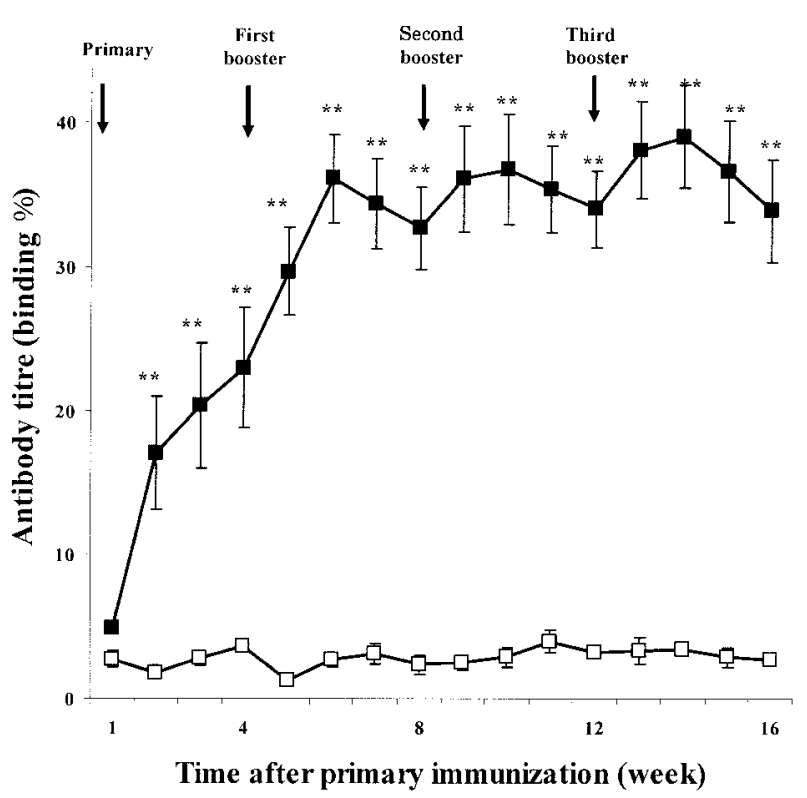

Figure 1 Plasma levels of inhibin binding in goats immunized against inhibin $\alpha$-subunit $(\square ; n=5)$ or control goats $(\square ; n=5)$ in plasma diluted 1:10. Arrows indicate time of immunization. Values are means \pm S.E.M. Inhibin antibody titres are expressed as the percentage of ${ }^{125}$ I-labelled bovine $32 \mathrm{kDa}$ inhibin bound at a plasma dilution of $1: 10 .{ }^{*} P<0 \cdot 01$ compared with corresponding values in controls.

\section{Statistical analysis}

Mean values \pm S.E.M. were calculated and analysed using two-way ANOVA. Duncan's multiple-range test was used for detection of significant differences using the SAS computer package (SAS 1987). Wilks' lambda correlation was made between inhibin antibody titres and ovulation rate.

\section{Results}

\section{Plasma anti-inhibin titres}

The time course of antibody development in immunized animals as determined by binding of ${ }^{125}$ I-labelled bovine inhibin is shown in Fig. 1. Antibodies that bound ${ }^{125} \mathrm{I}-$ labelled bovine inhibin were produced by all goats receiving the vaccine. Titres rose after primary immunization reaching $36 \cdot 2 \pm 3 \cdot 1 \%$ at $1: 10$ dilution within 6 weeks. In contrast, antibody titres in the control group remained low $(<3 \cdot 0 \%)$.

\section{Plasma concentrations of FSH and $\mathrm{LH}$}

The overall mean basal FSH concentrations for the 30-day period after the third booster immunization (PGshortened cycles) were significantly higher $(P<0 \cdot 05)$ in inhibin-immunized goats $(9 \cdot 2 \pm 0 \cdot 2 \mathrm{ng} / \mathrm{ml}, n=132)$ than in the controls $(5 \cdot 0 \pm 0 \cdot 2 \mathrm{ng} / \mathrm{ml}, n=132)$. In both groups, PG injection was followed by a preovulatory surge in FSH (immunized: $27 \cdot 1 \pm 2 \cdot 3$ vs control: $19 \cdot 9 \pm 0.8 \mathrm{ng} / \mathrm{ml}$; $P<0 \cdot 05)$ coincident with the LH surge (Fig. 2a). Plasma concentrations of LH did not differ significantly between inhibin-immunized and control goats (Fig. 2b). Overall, mean plasma LH values were $0.9 \pm 0.1 \mathrm{ng} / \mathrm{ml}$ in the immunized group and $1 \cdot 1 \pm 0 \cdot 1 \mathrm{ng} / \mathrm{ml}$ in the control group. The mean time interval between $\mathrm{PGF}_{2} \alpha$ injection and the occurrence of the preovulatory LH surge was significantly $(P<0 \cdot 05)$ shorter in the inhibin-immunized group than the control group $(53.9 \pm 1.5 \mathrm{~h}$ in the immunized group and $61.3 \pm 1.8 \mathrm{~h}$ in the control group).

\section{Oestradiol-17 $\beta$ and progesterone}

Plasma concentrations of oestradiol-17 $\beta$ rose after PGinduced luteolysis to reach a peak value which was significantly $(P<0 \cdot 01)$ higher in immunized goats $(47 \cdot 8 \pm 2 \cdot 9 \mathrm{pg} / \mathrm{ml}, n=15)$ than in controls $(24 \cdot 8 \pm 1 \cdot 7$, $n=15)$. The concentration then fell and remained relatively low until the next PG injection, with the exception of a smaller peak 4-5 days after oestrus (Fig. 3a). Three to four days after ovulation (ovulation was determined by ultrasonography as sudden disappearance of large follicles) the expected rise in the plasma concentrations of progesterone was observed in all goats, confirming that ovulation had occurred. Progesterone values were significantly $(P<0.05)$ higher in immunized compared with respective values in controls (Fig. $3 b$ ).

\section{Ovarian activity and ovulation rate}

After injection of $\mathrm{PGF}_{2} \alpha$, all goats exhibited oestrus and ovulated. The interval from $\mathrm{PGF}_{2} \alpha$ injection to onset of oestrus was significantly $(P<0 \cdot 05)$ shorter in the immunized group $(46.8 \pm 1 \cdot 8$ and $54.4 \pm 2.5 \mathrm{~h}$ in actively immunized and control goats respectively). Ovulation rates were recorded over three PG-shortened consecutive oestrous cycles after the third booster immunization against inhibin. There was around a 4-fold increase in ovulation rate in goats actively immunized against inhibin (Fig. 4). The mean ovulation rate was $1 \cdot 7 \pm 0 \cdot 3$ and $7 \cdot 6 \pm 1 \cdot 1$ in control and immunized groups respectively. There was a positive correlation $(r=0 \cdot 9, \quad P<0 \cdot 001)$ between inhibin antibody titre and ovulation rate. Figure 5 shows ultrasound images of ovaries of immunized goats containing many preovulatory follicles during the follicular phase and many corpora lutea during the luteal phase in the limited ovarian space, confirming multiple ovulation compared with control goats.

\section{Discussion}

In the present study, we have clearly demonstrated the efficacy of immunization against inhibin $\alpha$-subunit in 

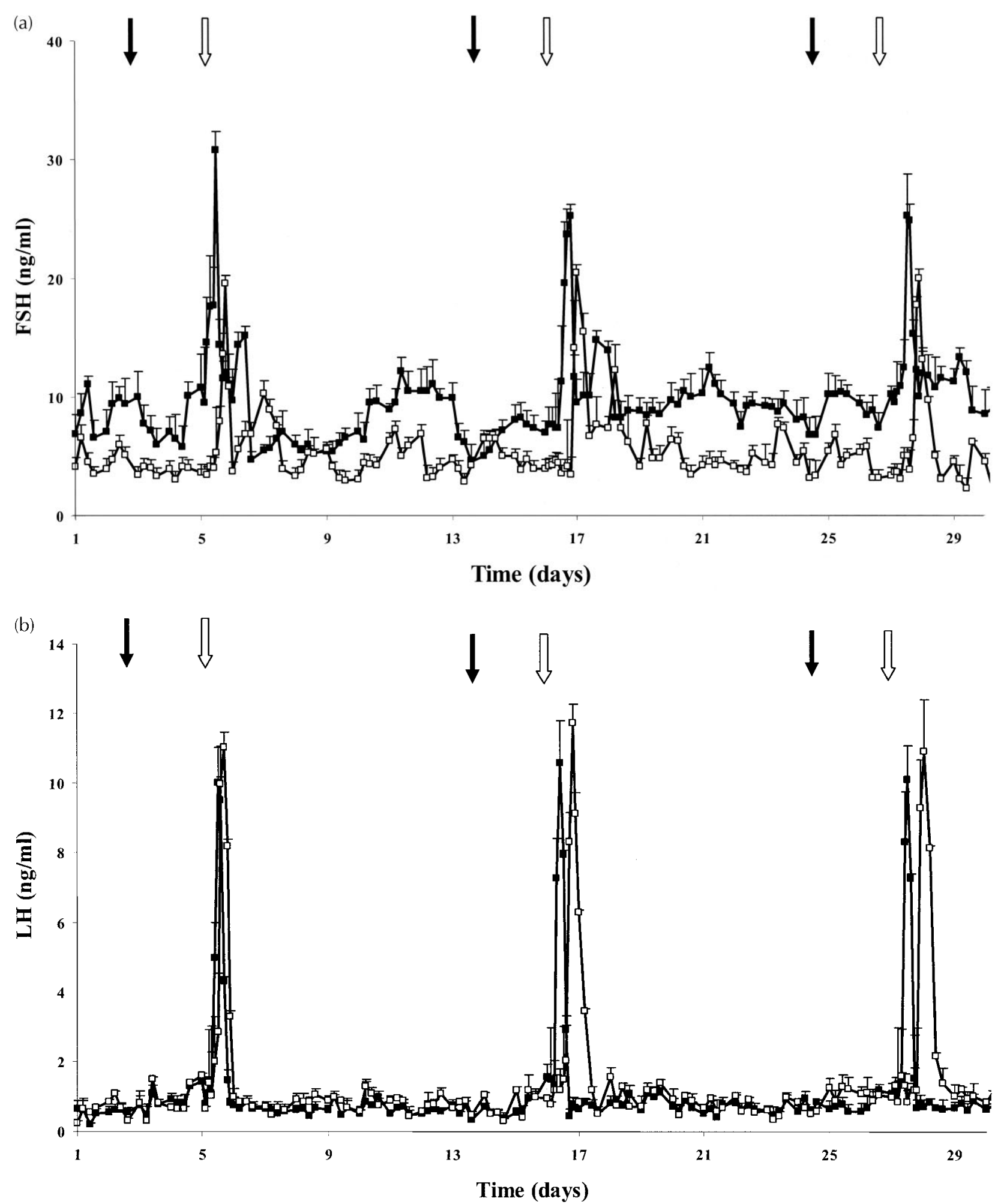

Figure 2 Plasma concentrations of FSH (a) and LH (b) in inhibin-immunized $(\boldsymbol{\square} ; n=5)$ and control goats $(\square ; n=5)$ during 30 days encompassing three consecutive periods of oestrus. Black arrows indicate PG injection and white arrows indicate oestrus. Values are means \pm S.E.M. 

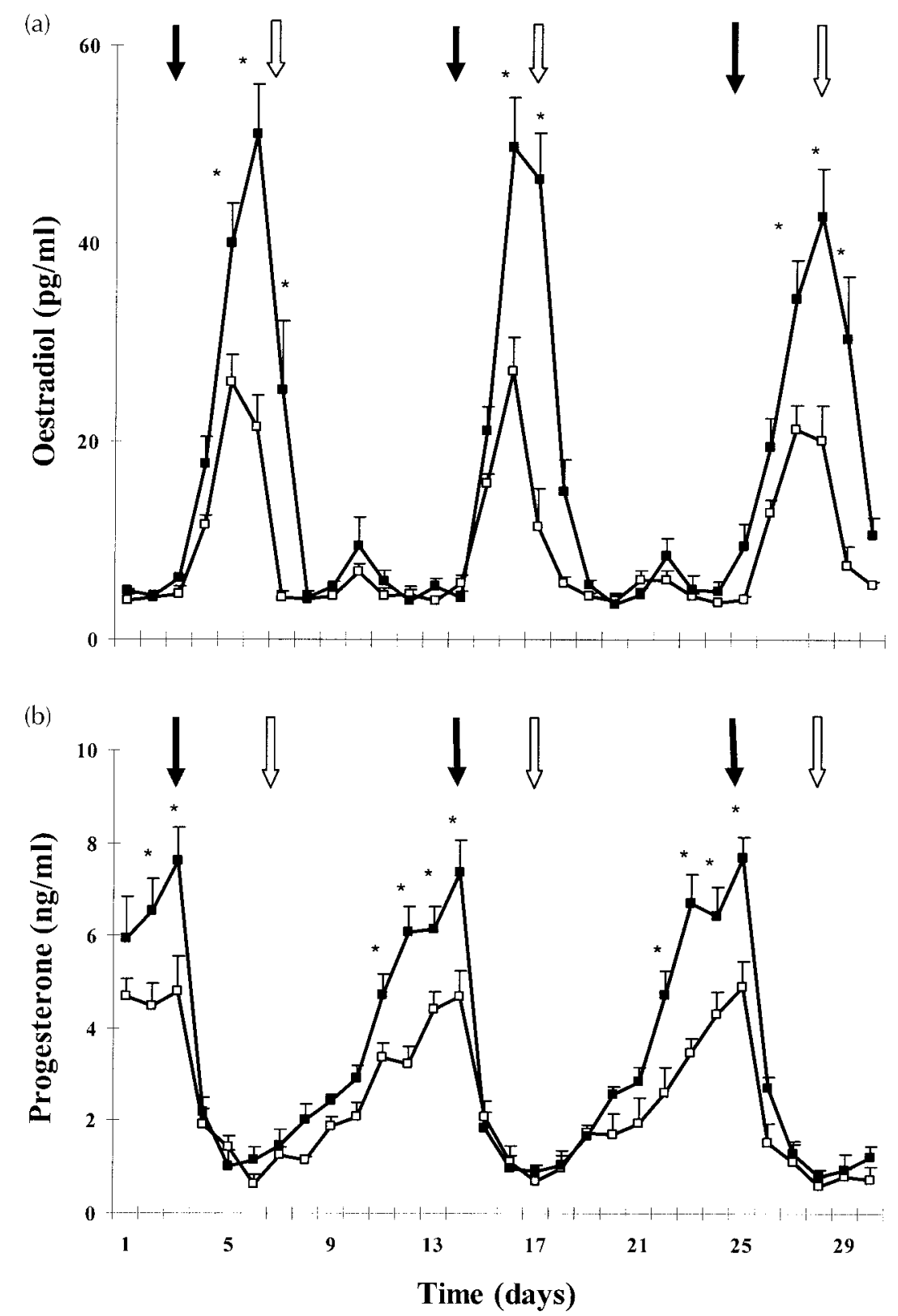

Figure 3 Plasma concentrations of oestradiol- $17 \beta$ (a) and progesterone (b) in inhibin-immunized $(\boldsymbol{\square} ; n=5)$ and control goats $(\square ; n=5)$ during 30 days encompassing three consecutive periods of oestrus. Black arrows indicate PG injection and white arrows indicate oestrus. Values are means \pm S.E.M. ${ }^{*} P<0.05$ compared with the control values.

increasing the ovulation rate in goats. We have also shown that superovulation is associated with elevated plasma concentrations of FSH. Immunization against inhibin stimulated an immune response and all immunized goats generated antibodies that bound ${ }^{125}$ I-labelled inhibin. Antibody binding was significant, confirming that the increased ovulation rate after immunization with synthetic peptides based on the inhibin $\alpha$-subunit was due to immunoneutralization of endogenous inhibin. Mean plasma concentrations of FSH were significantly higher in immunized animals compared with control animals throughout 30 days (during PG-shortened oestrous cycles). This provides further evidence that immunization against inhibin increased plasma concentrations of FSH and then increased ovulation rate. Increased FSH levels in the immunized group were in agreement with those reported 


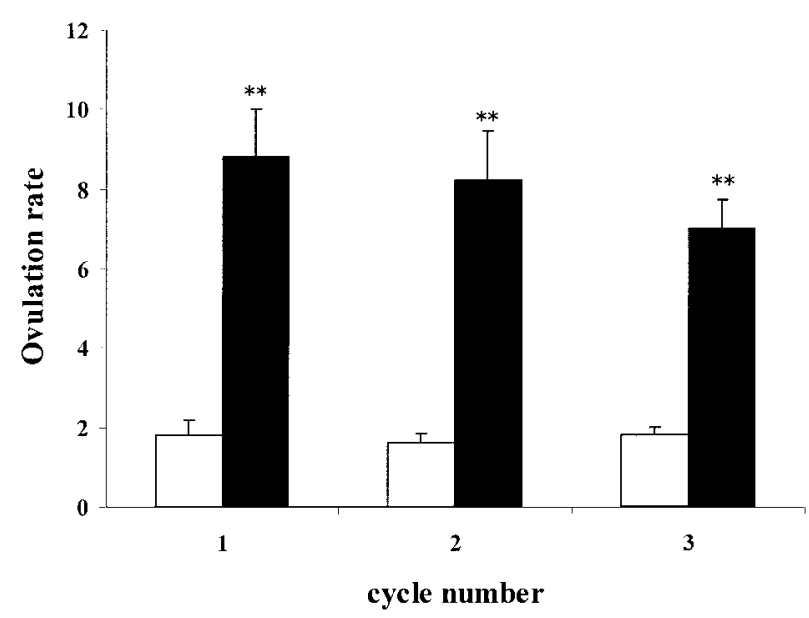

Figure 4 Ovulation rate in inhibin-immunized (solid bar; $n=5$ ) and control goats (open bar; $n=5$ ) during three consecutive PGshortened oestrous cycles after the third booster immunization. Values are means \pm S.E.M. ${ }^{*} P<0 \cdot 01$. in ewes (Mizumachi et al. 1990, Wrathall et al. 1990, 1992, Wheaton et al. 1992, Russell et al. 1994, Tannetta et al. 1997) and disagree with Hennies et al. (2001), who reported an increase in ovulation rate in inhibinimmunized goats without any change in FSH level. Immunoneutralization of endogenous inhibin was thought to result in diminished negative feedback on the anterior pituitary gland resulting in increased FSH secretion, subsequently increased follicular development and finally increased ovulation rate. In the present study, an approximately 4-fold increase in ovulation rate was observed following the third booster immunization. Similar findings were recorded in ewes (Anderson et al. 1998). In contrast to $\mathrm{FSH}$, there was no marked change in the LH profile between the immunized and the control goats. The lack of an effect on LH secretion recorded in inhibin-immunized goats contrasts with the findings of Hennies et al. (2001) who reported that LH levels were reduced in inhibinimmunized goats. However, in the present study,
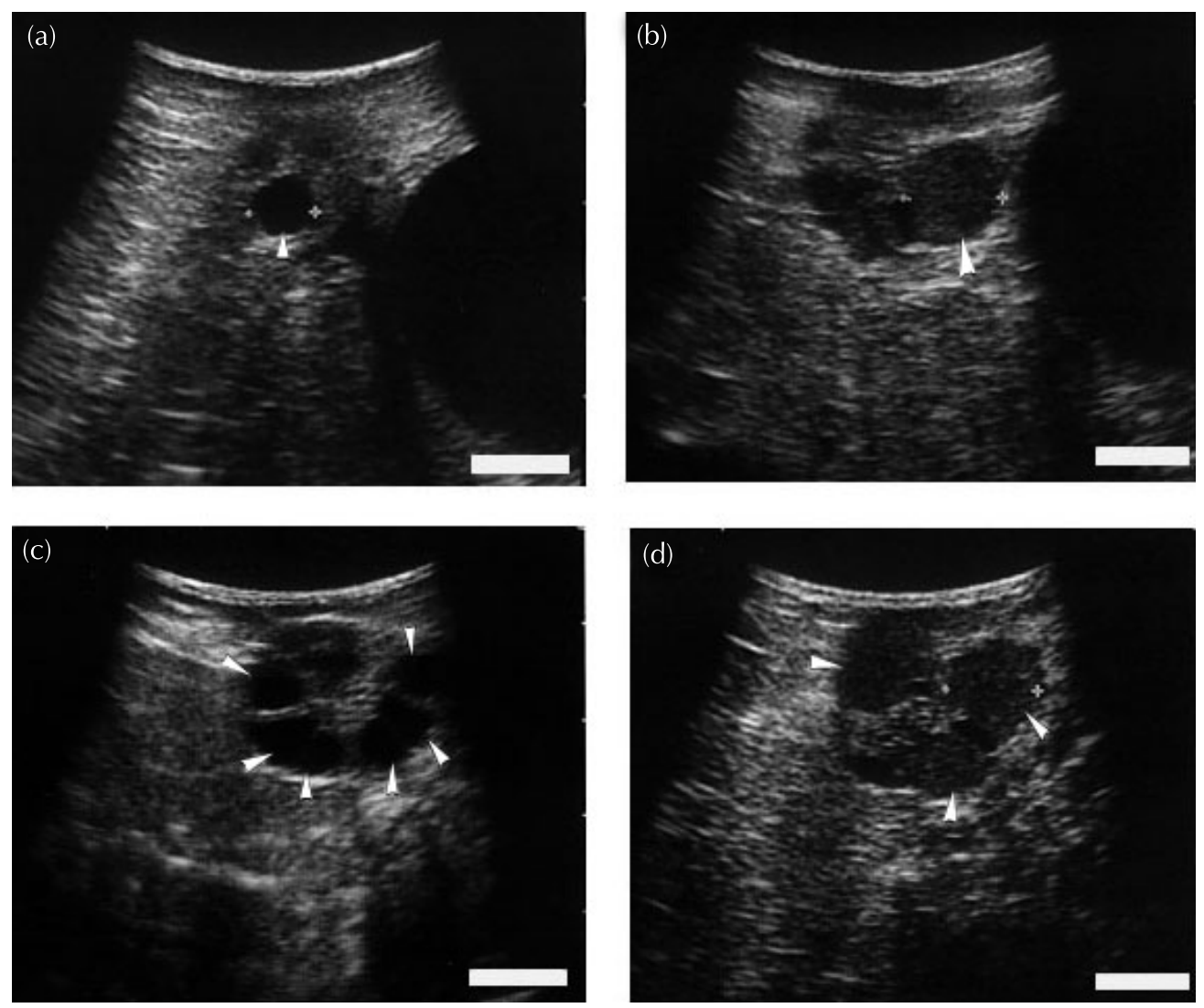

Figure 5 Ultrasound images of ovaries of goats produced by using a transrectal $7 \cdot 5 \mathrm{MHz}$ transducer and B-mode scanner. (a) The arrowhead indicates an antral follicle. (b) The arrowhead indicates a corpus luteum. (c) The arrowheads indicate multiple antral follicles. (d) The arrowheads indicate multiple corpora lutea. Note that there are many antral follicles and corpora lutea in inhibin-immunized goats (c and d) compared with control goats (a and b). Scale bar represents $10 \mathrm{~mm}$. 
immunized goats displayed an earlier preovulatory LH surge than control goats. This might be attributed to the increased amounts of oestrogen secreted by the large number of developing follicles in immunized goats (Campbell \& Scaramuzzi 1995). Similar results were recorded in ewes immunized against inhibin (Anderson et al. 1998). Plasma concentrations of oestradiol rose immediately after PG injection in all goats. The peak level of plasma concentrations of oestradiol-17 $\beta$ in the inhibinimmunized group was significantly higher than controls. This is similar to previous results recorded in goats (Hennies et al. 2001). The increase in plasma concentrations of oestradiol-17 $\beta$ is probably due to an increased number of oestrogenic follicles destined to ovulate. The progesterone levels in inhibin-immunized goats were significantly higher than in controls. The higher progesterone levels most likely reflect the increased ovulation rate and increased corpora lutea numbers in immunized goats.

In conclusion, the present study demonstrates that active immunization against the inhibin $\alpha$-subunit increases ovarian activity and ovulation rate, which is associated with elevated FSH secretion. Therefore, immunization of goats against inhibin could be used to generate increases in litter size or increased numbers of oocytes and/or embryos for multiple-ovulation embryo-transfer programmes.

\section{Acknowledgements}

We are grateful to Dr A F Parlow (National Institute of Diabetes and Digestive and Kidney Diseases, Beltsville, MD, USA) for providing RIA materials for ovine FSH and LH, Dr G D Niswender (Animal Reproduction and Biotechnology Laboratory, Colorado State University, Fort Collins, CO, USA) for providing antisera to oestradiol-17 $\beta$ (GDN 244) and progesterone (GDN 337) and Dr Y Mori (University of Tokyo, Bunkyo-ku, Tokyo, Japan) for antiserum to ovine LH (YM-18). This work was supported in part by the Ito Foundation, the Japan Livestock Technology Association and a Grant-in-Aid for COE Research (E-1) from the Ministry of Education, Science, Sports and Culture, Japan.

\section{References}

Akagi S, Kaneko H, Nakanishi Y, Takedomi T, Watanabe G \& Taya K 1997 Ovarian response and FSH profile in cows following injection of various doses of inhibin antiserum. Journal of Veterinary Medical Science 59 1129-1135.

Anderson ST, Bindon BM, Hillard MA \& O'Shea T 1998 Increased ovulation rate in Merino ewes immunized against small synthetic peptide fragments of inhibin $\alpha$-subunit. Reproduction, Fertility, and Development 10 421-433.

Araki K, Arai K, Watanabe G \& Taya K 2000 Involvement of inhibin in the regulation of follicle-stimulating hormone secretion in the young adult male Shiba goat. Journal of Andrology 21 558-565.
Campbell BK \& Scaramuzzi RJ 1995 Effect of acute immunoneutralization of inhibin in ewes during the late luteal phase of the oestrous cycle on ovarian hormone secretion and follicular development during the subsequent follicular phase. Journal of Reproduction and Fertility 104 337-345.

Dietrich E, Hennies M, Holtz W \& Voglmayr JK 1995 Immunization of goats against recombinant human inhibin $\alpha$-subunit: effects on inhibin binding, mating behavior, ovarian activity and embryo yield. Animal Reproduction Science 39 119-128.

Findlay JK \& Clarke IJ 1987 Regulation of FSH in domestic animals. Journal of Reproduction and Fertility 34 (Suppl) 27-37.

Findlay JK, Robertson DM, Clarke IJ, Klein R, Doughton BW, Xiao S, Russell DL \& Shukowski L 1992 Hormonal regulation of reproduction - general concepts. Animal Reproduction Science $\mathbf{2 8}$ 319-328.

Glencross RG, Bleach ECL, Wood SC \& Knight PG 1994 Active immunization of heifers against inhibin: effects on plasma concentrations of gonadotrophins, steroids and ovarian follicular dynamics during prostaglandin-synchronized cycles. Journal of Reproduction and Fertility 100 599-605.

Hennies M, Voglmayr JK, Dietrich E, Stollmann M, Moeller R \& Holtz W 2001 Hormonal response of female goats to active immunization against a recombinant human inhibin $\alpha$-subunit, and establishment of an enzyme-linked immunosorbent assay for caprine follicle-stimulating hormone. Reproduction in Domestic Animals 36 65-71.

Kaneko H, Nakanishi Y, Taya K, Kishi H, Watanabe G, Sasamoto S \& Hasegawa Y 1993 Evidence that inhibin is an important factor in the regulation of FSH secretion during the mid-luteal phase in cows. Journal of Endocrinology 136 35-41.

Konishi M, Aoyagi Y, Takedomi T, Itakura H, Itoh T, Yazawa S, Kishi H, Taya K, Watanabe G \& Kanagawa H 1996 Effect of active immunization of cattle against inhibin on ovarian follicular development and ultrasound-guided transvaginal follicular aspiration. Theriogenology 46 33-43.

Kusina NT, Meyer RL, Carlson KM \& Wheaton JE 1995 Passive immunization of ewes against an inhibin like peptide increases follicle-stimulating hormone concentrations, ovulation rate and prolificacy in spring-mated ewes. Journal of Animal Science $\mathbf{7 3}$ 1433-1439.

Ling N, Ying SY, Veno N, Esch F, Denoroy L \& Guillemin R 1985 Isolation and partial characterization of $\mathrm{M}_{\mathrm{r}} 3200$ protein with inhibin activity from porcine follicular fluid. PNAS 82 7217-7221.

Ling N, Ying SY, Veno N, Shimasaki S, Esch F, Holta M \& Guillemin R 1986 Pituitary FSH is released by a heterodimer of the $\beta$-subunits from the two forms of inhibin. Nature 321 779-882.

McCue PM, Carney NJ, Hughes JP, Rivier J, Vale W \& Lasley BL 1992 Ovulation and embryo recovery rates following immunization of mares against an inhibin alpha-subunit fragment. Theriogenology 38 823-831.

Mizumachi M, Voglmayer JK, Washington DW, Chen CL \& Bardin CW 1990 Superovulation of ewes immunized against the human recombinant inhibin $\alpha$-subunit associated with increased pre and postovulatory follicle-stimulating hormone levels. Endocrinology 126 1058-1063.

Mori Y \& Kano Y 1984 Changes in plasma concentrations of LH, progesterone and oestradiol in relation to the occurrence of luteolysis, oestrus and time of ovulation in Shiba goats (Capra hircus). Journal of Reproduction and Fertility 72 223-230.

Nambo Y, Kaneko H, Nagat S, Oikawa M, Yoshihara T, Nagamine N, Watanabe G \& Taya K 1998 Effect of passive immunization against inhibin on FSH secretion, folliculogenesis and ovulation rate during the follicular phase of oestrous cycle in mares. Theriogenology 50 545-557.

Pierson R A \& Ginther OJ 1988 Ultrasonic imaging of the ovaries and uterus in cattle. Theriogenology 29 21-37. 
Russell DL, Doughton BW, Tsonis CG \& Findlay JK 1994 Pituitary and ovarian function in ewes immunized against the amino-terminal peptide $(\alpha \mathrm{N})$ of inhibin $\alpha_{43}$-subunit. Journal of Reproduction and Fertility 100 115-122.

SAS 1987 Statistics, Version 6·11. Cary, NC: SAS Institute Inc.

Shi F, Ozawa M, Komura H, Yang P, Trewin AL, Hutz RJ, Watanabe G \& Taya K 1999 Secretion of ovarian inhibin and its physiologic roles in the regulation of follicle-stimulating hormone secretion during the estrous cycle of the female guinea pig. Biology of Reproduction $\mathbf{6 0}$ 78-84.

Shi F, Ozawa M, Komura H, Watanabe G, Tsonis CG, Suzuki AK and Taya K 2000 Induction of superovulation by inhibin vaccine in cyclic guinea-pig. Journal of Reproduction and Fertility 118 1-7.

Takedomi T, Kaneko H, Aoyagi Y, Konishi K, Kishi H, Watanabe G \& Taya K 1997 Effects of passive immunization against inhibin on ovulation rate and embryo recovery in Holstein heifers. Theriogenology 47 1507-1518.

Tannetta DS, Fray MD, Wrathall JHM, Bleach ECL, Glencross RG \& Knight PG 1997 Effects of supplementary treatment with bovine growth hormone on hormonal and ovulatory responses to inhibin immunization in ewes. Journal of Reproduction and Fertility 110 $255-262$.

Taya K 1993 Role of inhibin in regulation of FSH secretion and folliculogenesis in mammals. Current Trends in Experimental Endocrinology 1 97-116.

Taya K \& Watanabe G 1999 Inhibin as a key hormone in determining species-specific ovulation rates in mammal. In Recent Progress in Molecular and Comparative Endocrinology, Hormone Research
Center, pp 134-143. Eds HB Known, JMP Joss \& S Ishii. Kwangju: Chonman National University.

Taya K, Watanabe G \& Sasamoto S 1985 Radioimmunoassay for progesterone, testosterone and oestradiol $17 \beta$ using

${ }^{125}$ I-iodohistamine radioligands. Japanese Journal of Animal Reproduction 31 186-197.

Vale W, Rivier J, Vaughan J, McClintock R, Corrigan A, Woo W, Karr D \& Spiess J 1986 Purification and characterization of an FSH releasing protein from porcine ovarian follicular fluid. Nature 321 776-779.

Wheaton J, Carlson K \& Kusina N 1992 Active and passive immunoneutralization of inhibin increases follicle stimulating hormone levels and ovulation rate in ewes. Biology of Reproduction 47 361-367.

Wrathall JHM, McLeod BJ, Glencross RG, Beard AJ \& Knight PG 1990 Inhibin immunoneutralization by antibodies raised against synthetic peptide sequences of inhibin $\alpha$ subunit: effects on gonadotrophin concentrations and ovulation rate in sheep. Journal of Endocrinology 124 167-176.

Wrathall JHM, McLeod BJ, Glencross RG \& Knight PG 1992 Effects of active immunization against a synthetic peptide sequence of the inhibin $\alpha$-subunit on plasma gonadotrophin concentrations, ovulation rate and lambing rate in ewes. Journal of Reproduction and Fertility 95 175-182.

Received in final form 20 January 2003

Accepted 4 February 2003 